Severe emotional deprivation with reversible failure of growth hormone release has been recognized as an important cause of growth failure. ${ }^{4}$ This work in Newcastle has documented the association of adverse family circumstances with growth retardation in children in whom growth hormone levels are normal. Factors such as long periods of paternal unemployment, imprisonment, parental separation, and the state of the home assessed by a health visitor were used to give an objective social score, from which it was concluded that in at least one third of these small, normal children impaired physical development was due to the poor home environment. In addition, children from emotionally deprived homes also had significantly lower intellectual attainment than children from appropriate control families without such adverse home backgrounds.

The relative role of genetic and environmental factors cannot yet be fully unravelled, but an association has been established between growth retardation and impaired intelligence on the one hand and particularly bad family circumstances on the other. Short stature should thus alert the physician, the family doctor, community physician, or paediatrician to the possibility of severe social deprivation. The remedy may well be out with his power, lying rather with society's attitude to the less-favoured than in the efficiency of such social agencies he may call upon. But for future generations a feeling of obligation to the underprivileged must be backed with improved educational services in general and instruction into the responsibilities of parenthood, in particular, especially in the most socially deprived areas.

1 Harris, F., Medicine, 1974, 27, 1600.

2 Lacey, K. A., and Parkin, J. M., Lancet, 1974, 1, 42.

3 Lacey, K. A., and Parkin, J. M., Archives of Diseases in Childhood, 1974, 49, 417 .

${ }^{4}$ Powell, G. F., Brasel, J. A., and Blizzard, R. M., New England Fournal of Medicine, 1967, 276, 1271 .

\section{Review of Meniscectomies}

Meniscectomy is one of the most popular orthopaedic operations, but as Fairbank ${ }^{1}$ pointed out in 1948 it is not a wholly innocuous procedure. He found radiographic changes in $37 \%$ of 107 patients examined from three months to four years after operation. These included ridging and flattening of the appropriate femoral condyle and narrowing of the joint space, either singly or in combination. He concluded that meniscectomy interferes at least temporarily with the mechanics of the joint and suggested that the changes seen might be the precursors of osteoarthritis.

More recently Jackson ${ }^{2}$ compared the radiographs of both knees in 577 patients five or more years after operation on one knee only. He found that degenerative change occurred in $21 \%$ of post-meniscectomy knees and in only $5 \%$ of the controls. Though degeneration increased in both knees with the length of follow-up meniscectomy precipitated a much greater change. He also found that the length of time that the patient had had his symptoms before surgery had no effect on the severity of the degeneration found later. Jackson stressed that radiographic changes in the knee did not necessarily mean that the patient had symptoms in the joint, but he thought that a more conservative attitude to meniscectomy should be adopted. Even at arthrotomy he advised that all other structures should be examined carefully before a normal-looking meniscus was excised. He suggested that a long period of preoperative observation be undertaken if there was any doubt that the meniscus was torn-and added that there might be medicolegal implications, since a man whose meniscus was removed in his 20 s would risk osteoarthrosis in the joint by his 50 s, and a manual worker might need to change his job.

A more detailed report of the long-term results of meniscectomy has now been published by Johnson et al..$^{3}$ from Iowa. They examined 99 patients 5-37 years after surgery. All these patients had had the operation performed on one knee only, the other knee being used as a control and they found that $42.5 \%$ had satisfactory results and $57.5 \%$ unsatisfactory. Men were found to have recovered better from surgery than women, especially if the medial meniscus alone had been excised; if the posterior horn was not excised the results were unsatisfactory; while the status of the surgeon performing the operation did not affect the prognosis. In contrast with Jackson's experience, Johnson and his colleagues found there was a connexion between the result and the length of time between onset of symptoms and surgery. They acknowledged that they differed from other authors on this point, and suggested that it might not be the length of time the patients had had his symptoms but the trauma of repeated locking and collapsing that led to the poor prognosis. More patients had ligamentous laxity postoperatively than preoperatively, and these patients had unsatisfactory results. Rotational instability was increased and passive motion reduced in some patients. These were also associated with poor results, as was quadriceps atrophy, which occurred in 30 of the 99 patients. At least one of Fairbank's changes on radiography was found in $74 \%$ of the knees, and the frequency of unsatisfactory results increased with the number of changes found.

So from both sides of the Atlantic there is evidence of the many problems that may follow excision of a structure whose function is not fully understood. The message from these studies, however, is easy to understand: a torn meniscus giving symptoms must be excised, but if the meniscus can be left in the joint it should be.

1 Fairbank, T. J., Fournal of Bone and Foint Surgery, 1948, 30, 664.

2 Jackson, J. P., British Medical fournal, 1968, 2, 525.

3 Johnson, R. J., et al., fournal of Bone and foint Surgery, 1974, 56, 719.

\section{Biochemical Basis of Migraine}

The idea that a unifying biochemical cause underlies both the migrainous diathesis and the precipitation of attacks of migraine has always been seductive-and receives some support from the observed effect of diet. A proportion of migraine sufferers claim that their attacks are triggered by certain foods, notably cheese, chocolate, and citrus fruits, and, even more frequently, by alcohol, particularly red wine. Unfortunately, avoidance of these substances seldom leads to cure, and the relationship appears to be complex. Even though in patients who had observed an adverse effect of chocolate the consumption of disguised chocolate under controlled conditions did not induce migraine, ${ }^{1}$ the dietary clue is promising. Tyramine, already incriminated in the headache and hypertension induced by eating cheese in patients taking monoamine oxidase inhibitors, ${ }^{2}$ was at first suspected, though hypertension is not a feature of the migraine attack. A failure to metabolize tyramine has been reported in some migrainous subjects, ${ }^{3}$ but under laboratory conditions tyramine does not induce migraine, ${ }^{4}$ and the E.E.G. changes reported to follow its ingestion are difficult to equate with the underlying mechanisms of headache. ${ }^{5}$ 
Chocolate does not contain tyramine but has a relatively high content of phenylethylamine; and so Sandler, Youdim, and Hanington ${ }^{6}$ administered either lactose or $3 \mathrm{mg}$ of phenylethylamine (the approximate content of a small bar of chocolate) to 46 patients who claimed that their migraine was precipitated by chocolate. They did not know the content of the capsules, but in each case the lactose was given first; and ten of them did not in fact take the test substance, five of them developing headache after lactose. In those who completed the trial there was a markedly increased incidence of headache after phenylethylamine, though four patients had symptoms only after lactose: a random order of administration of placebo and drug might have been advantageous. Headache characteristically followed phenylethylamine after an interval of some 12 hours, and Sandler ${ }^{7}$ has suggested that this delay may be due to the triggering agent releasing vasoactive substances from the lungs with a secondary effect on cerebral vasculature. Facilitated release of such substances might be due to failure to inactivate monoamines.

This aspect was investigated ${ }^{6}$ by the measurement of MAO activity in the platelets of migraine sufferers, whether dietinduced or not, compared with nonmigrainous subjects. A highly significant reduction in the ability to oxidase both phenylethylamine and tyramine was found in both groups of migraine subjects compared with the normal, and to a lesser degree oxidation of dopamine and 5-hydroxytryptamine was also impaired. It is not known to what extent platelet MAO levels reflect those in other organs, notably the lungs, nor whether the defect can be localised to the "B" type of MAO for which phenylethylamine is a preferred substrate. At present the evidence for a biochemical defect is more convincing than that of its immediate relevance to the complex clinical phenomena of the migraine attack.

\footnotetext{
${ }^{1}$ Moffett, A. M., Swash, M., and Scott, D. F., fournal of Neurology, Neurosurgery and Psychiatry, 1974, 37, 445.

2 Asatoor, A. M., Levi, A. J., and Milne, M. D., Lancet, 1963, 2, 733.

3 Smith, I., et al., Nature, 1971, 230, 246.

4 Moffett, A., Swash, M., and Scott, D. F., fournal of Neurology, Neuro-

surgery and Psychiatry, 1972, 35, 496.
5 Scott, D. F., Moffett, A., and Swash, M., Epilepsia, 1972, 13, 365.

- Sandler, M., Youdim, M. B. H., and Hanington, E., Nature, 1974, 250, 335.

7 Sandler, M., Lancet, 1972, 1, 618.
}

\section{Late Onset of Puberty}

Adolescent girls may come to their doctors at any stage of puberty because they or their mothers think that they are lagging behind their contemporaries. A clear idea of the range of normal development is needed for detection and treatment of the abnormal and for an accurate prognosis to be given to those girls who are later in development than average. These subjects were discussed at a symposium at the Royal College of Physicians of Edinburgh, recently published. ${ }^{1}$

The onset of menstruation marks one change in a girl from child to adolescent. In Britain the average age of onset is $13 \frac{1}{2}$ years and in $95 \%$ of girls it is between 11 and 15 . If the spontaneous onset of menstruation occurs later than 16, it can be regarded as a late menarche. The menarche does not occur in isolation but is preceded by other physical signs of puberty -a sudden acceleration of growth in height and development of the breasts and of pubic and axillary hair. The order in which these appear is somewhat variable, but menstruation usually occurs last. Puberty requires normal function and maturation of the hypothalamic, pituitary, ovarian, and adrenal axes. In addition, the menarche requires development and patency of the genital tract. Delayed menarche can occur in normal girls, but can also be due to malfunction of any of these organs.

Development of the breasts is usually the first sign of puberty to appear, but rarely pubichair may precede it. Either may occur from $8 \frac{1}{2}$ years onwards, and most girls have shown signs of breast development by the age of 13 years, but normal puberty has occurred ${ }^{1}$ in girls whose breasts have not started to grow until the age of 15 .

The breast shows gradual enlargement from a small mound to the adult breast. The areola and nipple also enlarge. The menarche never occurs until the breasts have progressed beyond the bud stage to the rounded contour of the young breast, and usually it occurs when the areola and nipple have enlarged sufficiently to form a secondary mound above the level of the rest of the breast. The growth spurt occurs relatively early in the course of breast development. The time from the beginning of breast development to the menarche may be anything from six months to five years but the average $^{2}$ is 2.3 years. If the menarche is delayed but examination of the patient shows that the breasts are developing though not fully mature and body hair growth is advancing, then it is most probable that the menarche will occur normally. Pubic and axillary hair usually start growing after breast development has begun but sometimes precedes it.

The average girl grows at a rate of $5 \mathrm{~cm}$ a year in late childhood; then at puberty a growth spurt occurs before the onset of the menses. The growth rate increases to reach a peak of about $9 \mathrm{~cm}$ a year, and during that year a girl gains from 6 to $11 \mathrm{~cm}$ in height. The average age at which the growth spurt occurs is 12 years ${ }^{2}$-about the same time as the breast development. By the time the periods occur the growth rate is slowing down again. When the menarche is late this growth spurt may be delayed too, but this can be detected only by regular six-monthly standardized height measurements. Very small stature and slow growth may be associated with chromosomal abnormalities such as Turner's syndrome or $45 \mathrm{X}$ females. These short girls require investigation, and if signs of puberty are also absent, it is worth undertaking specialist investigation as soon as 14 years.

Associated with the growth spurt there is maturation of the skeleton. Menstruation generally occurs between the skeletal ages of 13 and 14 years and it is said ${ }^{1}$ never to have been seen in a girl with a skeletal age of less than 12.5 years or more than 14.5 years. Thus a girl with a late menarche whose bone age is less than 14.5 years may still experience normal onset of menstruation but if her bone age is more than 14.5 years she is unlikely to do so.

A girl complaining of primary amenorrhoea who has normal progressive secondary sexual development need not, then, be investigated until the age of 16 unless she or her mother is particularly concerned. She should be examined to confirm patency of the lower genital tract and to assess the development of the breasts and body hair. Her height should be measured two or three times a year. At the age of 16 specialist investigation should be done to exclude rare genital tract abnormalities, endocrine disorders, or chromosomal abnormalities. The administration of hormones to normal girls with delayed puberty is not advisable since it may cause premature cessation of growth.

\footnotetext{
1 Marshall, W. A., in Symposium Puberty and Adolescence, ed. A. T. Proudfoot, p. 13-15. Edinburgh, Royal College of Physicians of Edinburgh, 1974 .

2 Marshall, W. A., and Tanner, J. M., Archives of Disease in Childhood, $1969,44,291$.
} 